\title{
Descriptive analysis of phonological aspects among Hindi-speaking children with intellectual disability
}

\author{
Ramandeep Kaur*, T. A. Subbarao \\ Dr. M.V. Shetty College of Speech and Hearing, Mangalore University, Kavoor, Mangalore-575015, Karnataka, India
}

\begin{abstract}
Phonology refers to the speech sound systems of a language. The term 'phonemic' refers to speech sound use. Most of the previous research reveals that phonological skills develop with age and thus older children had more accurate speech and fewer error patterns in their speech. The present study aimed to obtain extensive phonological data among in Hindi-speaking typically developing children across age-matched children with intellectual disability. The results revealed that phonology develops significantly with the age. Thus, older children had more accurate production and fewer error patterns in their speech relative to younger group. Also, typically developing children had a better control over their phonological aspects compared to children with intellectual disability. A comparison with related studies has been discussed clearly in the paper which reveals a number of studies supporting the finding. The present study has significant implications for assessment of developmental speech disorders among Hindi-speaking Indian population.
\end{abstract}

Key words: Descriptive analysis; Phonology; Hindi-speaking children; Intellectual disability.

\section{Introduction}

Language refers to a systematic and conventional use of sounds (signs or symbols) for the purpose of communication and expression (Crystal, 1995). The experts in language termed as 'Speech language pathologists' focus on the development of language not only among normal children but more precisely among the children with language disorders. A universal understanding and experience of Speech language pathologists shows that a large population among language disordered children who seek therapy in clinics in India is that of Mental Retardation, currently known as, Intellectual disability. However, there is no hard data to make accurate interpretation. The next sections will focus on language performance of typically developing children, followed by children with intellectual disability. The term Mental Retardation and Intellectual Disability are used interchangeably in the discussion to maintain ease of understanding.

Received: 20-09-2017; Accepted 12-10-2017; Published Online 16-10-2017

*Corresponding Author

Ramandeep Kaur, Dr. M.V. Shetty College of Speech and Hearing, Mangalore University, Kavoor, Mangalore-575015, Karnataka, India
Phonological Development among typically developing children

During the development of language among typically developing children, the phonological and communicative acquisitions precede and thus prepare the child with the process of language acquisition. By 4-6 months a child begins to babble until the first words arrive at 1-1.6 years. Babbling appears to lead the child into words. Before words appear, children seem to have already acquired some communicative skills, generally requesting and asserting skills (Bruner, 1975; Bates, 1976). Consequently, the first words are produced between 10-15 months of age. These are hard to distinguish from the 'protowords'. These words may be context bound, situation-specific or function-specific and referential (Hoff, 2009). Among initial words, the noun meanings are much consistent to verb meanings (Gertner \& Boroditsky, 2001). Once the child hits the 8-12 month range the child engages in canonical babbling. This jargon babbling with international contours the language being learned (Owens, 2012). From 12-24 months, babies can recognize the correct pronunciation of familiar words. Babies 
will also use phonological strategies to simplify word pronunciation. By 24-30 months awareness of rhyme emerges as well as rising intonation. By 36-60 months, phonological awareness continues to improve as well as pronunciation. By 6-10 years, children can master syllable stress patterns which helps distinguish slight differences between similar words (Eva, 2011).

One of the issues we have been investigating is the nature of the constraints on the shape of children's early Prosodic Words. This appears to be depending on the distribution of word and foot structures found in the target language. Recent research has also examined the development of syllable structures (Paul, 2007). Some of this work finds that coda consonants are more likely to be produced in stressed and final syllables, both of which exhibit increased duration, suggesting that this facilitates the articulation of more segments. Other research has focused on the acquisition of word-final clusters, raising questions about the competing contributions of frequency, morphology, and structural/sonority / articulatory factors in predicting the course of cluster acquisition across languages (Paul, 2007). Mc. Namara \& Antony (2010) revealed that Phonological contrasts and Phonotactics which develop at early stages, guide the word segmentation and all other lexical feature development in future.

\section{Intellectual Disability}

Intellectual disability is a disability characterized by significant limitations both in intellectual functioning and in adaptive behavior as expressed in conceptual, social, and practical adaptive skills. This disability originates before age 18 (AAID, 2009).

Children with Intellectual disability learn more slowly than a typical child. Children may take longer to learn language, develop social skills, and take care of their personal needs, such as dressing or eating. Learning will take them longer, require more repetition, and skills may need to be adapted to their learning level. Nevertheless, virtually every child is able to learn, develop and become a participating member of the community.

\section{Phonological Development in Intellectually Disabled}

Most children with intellectual disability acquire a language system and functional speech. The rate and extent at which a child learns language is in proportion to the degree of the intellectual disability. The more extensive the intellectual disability is, the harder it is for the child to learn language.

The investigations of pre-speech development suggest that infants with intellectual disability are nearly typical in this domain. Various studies have documented strong similarities in the amount of vocalisations produced, particularly at the age of canonical babbling and in the characteristics of consonants and vowels occurring during the canonical babbling (Smith \& Stoel-Gammon, 1996; Oller, Lynch \& Urbano, 1992, Stoel-Gammon, 2001). Although the major investigations showed no difference between pre-linguistic development of infants with mental retardation and their non-retarded peers, the canonical babbling appears to be delayed by about 2 months and phonological development also appears to be substantially delayed (Oller, Lynch \& Urbano, 1992, Stoel-Gammon, 2001).

During the transition from babbling to speech, most children with intellectual disability exhibit substantial delay in the appearance of first words, in spite of near-normal babbling patterns (Smith, 1977; 1984; Stoel-Gammon, 2001). Moreover, the phonological processes seen in typically developing children continue to persist in mentally retarded children till adolescence and adulthood (Chapman, 1995; Stoel-Gammon, 2001).

Research on babbling by Oller and his colleagues among infants with mental retardation as compared to normally developing infants showed that infants with mental retardation were about two months behind normally developing group (Lynch, Oller, Eilers, \& Basinger, 1990; Steffens, Oller, Lynch \& Urbano, 1992; Oller, 2005) and more over babbling was significantly less stable as compared to normally developing infants due to motor delays andhypotonicity that are characteristic of mentally retarded children (Lynch et al., 1990).

Subba Rao (1995) suggested that the language development in children with intellectual disability follow the same pattern as typically developing children, though with a significant delay depending upon the severity of retardation. The errors that are evident among the children with intellectual disability show various similarities in the types, not only across typically developing children but also across the varying severities. 
Aim of the Study

The present study aims to obtain extensive phonological data in Hindi-speaking intellectually disabled children and its comparison to the typically developing children at two group levels of Mental Age 4-5 years and Mental Age 5-6 years.

\section{Method}

The study envisaged obtaining an audio-video taped conversational sample with normally speaking and the MA matched children with ID and subjecting the language data to phonological analysis. The overall guidelines provided by the LARSP (Crystal et al., 1976 and 1989) are used for transcription of the sample and analysis of response patterns.

\section{Subjects}

20 Typically developing children and 60 children with intellectually disabled were selected for the present study.

Normal Subjects: Twenty normal school going children in the age range of 4 years to 6 years were selected and divided into 4 subgroups of 6 monthly age range. Subsequently, during the selection of ID subjects, mental age (MA) estimates were available so as to allow classification into two groups of 4-5 years and 5-6 years.

Subjects with Intellectual Disability: Sixty children were selected from different special schools for children with ID in Delhi and Haryana regions. All the children were tested within the preceding year by a trained psychologist and Mental Age (MA) estimates were available in school records. The common tests used for assessment were Binet-Kamath test of intelligence, Vineland Social Maturity Scale and Seguin Form Board, but predominantly the assessment depended upon school records for Mental age details.

\section{Data Collection}

Following the guidelines of LARSP (Crystal et al., 1976 and 1989) on sample collection, a series of toys and pictures were used.
Table 1. Materials used for sample collection

\begin{tabular}{ll}
\hline & Doll House \\
Toys and Play Materials & Building blocks \\
& Toy Cars and Toy Train \\
& Kitchen Set \\
& Paper-pencil \\
& Road Traffic \\
List of Pictures & Village Scene \\
& Birthday Party \\
& City Scene \\
Topics for elicited & Family \\
Responses & School Life \\
& Television Programmes \\
& and Cartoon Scenes \\
& Favourite clothes/music \\
\hline
\end{tabular}

\section{Results}

The conversational language samples of typically developing children and children with ID were recorded during play time. This section targeted production of Hindi vowels and consonants. Consonant sounds were further sub-divided into various types based on place and manner of articulation.

\section{Within Group Comparison}

Typically Developing Children: Comparison within the group revealed that most of the phonemes among typically developing children develop by 5-5.5 years. Table 2 illustrates development of various phonemes across different age groups. Specifically, velars and vowels develop within 4 years of age followed by Palatal, alveolar, dental and labiodental phonemes which start appearing by 4 years but complete in development by 5 years. Retroflex, apico palatal and pharyngeal sounds do not appear until 4.5 years and get completed by 6 years of age. Moreover, statistical analyses using Fishers exact test reveals apico palatal and pharyngeal sounds to be significantly different across the age groups. This is clearly illustrated in Figure 1.

\section{Consonants}

As indicated in Table 2, among the consonant sounds, it is noted that most of typically developing children achieve the development of consonants by 6 years of age. It is observed that by 6 years, all the typically developing children complete their phonological repertoire with all sounds present adequately in all the word positions, except for voiced Alveolar Fricatives, voiced Velar Fricatives, velar nasals, alveolar flap and palatal retroflex. 
Descriptive analysis of phonological aspects among Hindi-speaking children

Sounds which complete their development at all positions by 4 years of age are:

1. Bilabial stops

2. Velar Stops

3. Voiceless Labio-dental Fricatives

4. Inter-dental Fricatives

5. Voiceless Velar fricatives

6. Bilabial nasal

7. Alveolar Nasal

8. Lateral Alveolar Liquids

9. Aspirated Bilateral Stops
Sounds which develop within 4-6 years of age are:

1. Alveolar Stops

2. Palatal Affricates

3. Voiced Labio-dental Fricatives

4. Voiceless Alveolar Fricatives

5. Palatal Fricative

6. Semi-vowels (Bilabial and Palatal)

7. All other Aspirated Sounds

Table 2. Consonant Development among Typically Developing Children

\begin{tabular}{|c|c|c|c|c|c|c|c|c|c|c|}
\hline & \multicolumn{10}{|c|}{ Phonology } \\
\hline & \multicolumn{2}{|c|}{ 4-4.5 years } & \multicolumn{2}{|c|}{ 4.5-5 years } & \multicolumn{2}{|c|}{ 5-5.5 years } & \multicolumn{2}{|c|}{ 5.5-6 years } & \multicolumn{2}{|c|}{ Fisher's Exact Test } \\
\hline & Count & $\%$ & Count & $\%$ & Count & $\%$ & Count & $\%$ & P value & Comments \\
\hline Velar & 5 & 100 & 5 & 100 & 5 & 100 & 5 & 100 & (1) & \\
\hline Palatal & 1 & 20 & 2 & 40 & 5 & 100 & 5 & 100 & 0.011 & *Significant \\
\hline Alveolar & 0 & 0 & 2 & 40 & 4 & 80 & 5 & 100 & 0.008 & *Highly Significant \\
\hline Dental & 3 & 60 & 4 & 80 & 5 & 100 & 5 & 100 & 0.230 & \\
\hline Labio Dental & 3 & 60 & 5 & 100 & 5 & 100 & 5 & 100 & 0.083 & \\
\hline Retro & 0 & 0 & 0 & 0 & 0 & 0 & 0 & 0 & • & \\
\hline Apico Palatal & 0 & 0 & 2 & 40 & 4 & 80 & 5 & 100 & 0.008 & *Highly Significant \\
\hline Pharyngeal & 0 & 0 & 2 & 40 & 5 & 100 & 5 & 100 & 0.002 & *Highly Significant \\
\hline
\end{tabular}

Vowels

Among the Vowels, it is noted that most of the vowel sounds are achieved within 4years of age. The acquisition of vowels has been described in the Table 2. As per the table, it is noted that major vowel development completes by the age of
4 years. The across group comparison shows that a few long vowels (/o:/, /e/) as well as complex diphthongs (/iu/, /ua:n/, /ai/) remain substituted by simpler form until 5years of age after which the development completes.

Table 2. Vowel development chart

\begin{tabular}{|c|c|c|c|c|}
\hline Vowels & 4.0-4.5 years & 4.5-5.0 years & 5.0-5.5 years & $5.5-6.0$ years \\
\hline /a/ & Acquired & Acquired & Acquired & Acquired \\
\hline /a:/ & Acquired & Acquired & Acquired & Acquired \\
\hline /i/ & Acquired & Acquired & Acquired & Acquired \\
\hline /i:/ & Acquired & Acquired & Acquired & Acquired \\
\hline$/ \mathrm{u} /$ & Acquired & Acquired & Acquired & Acquired \\
\hline /u:/ & Acquired & Acquired & Acquired & Acquired \\
\hline /e/ & Substituted by /ae/ & Substituted by /ae/ & Acquired & Acquired \\
\hline /o/ & Acquired & Acquired & Acquired & Acquired \\
\hline /o:/ & Substituted by /o/ & Substituted by /o/ & Acquired & Acquired \\
\hline /ae/ & Acquired & Acquired & Acquired & Acquired \\
\hline /ai/ & Substituted by /e/ & Substituted by /e/ & Acquired & Acquired \\
\hline /ia/ & Acquired & Acquired & Acquired & Acquired \\
\hline /ie/ & Acquired & Acquired & Acquired & Acquired \\
\hline /ui/ & Acquired & Acquired & Acquired & Acquired \\
\hline /ua:n/ & Substituted by /ua:/ & Substituted by /ua:/ & Acquired & Acquired \\
\hline /oi/ & Acquired & Acquired & Acquired & Acquired \\
\hline /oe/ & Acquired & Acquired & Acquired & Acquired \\
\hline /iu/ & Substituted by /u/ & Acquired & Acquired & Acquired \\
\hline
\end{tabular}




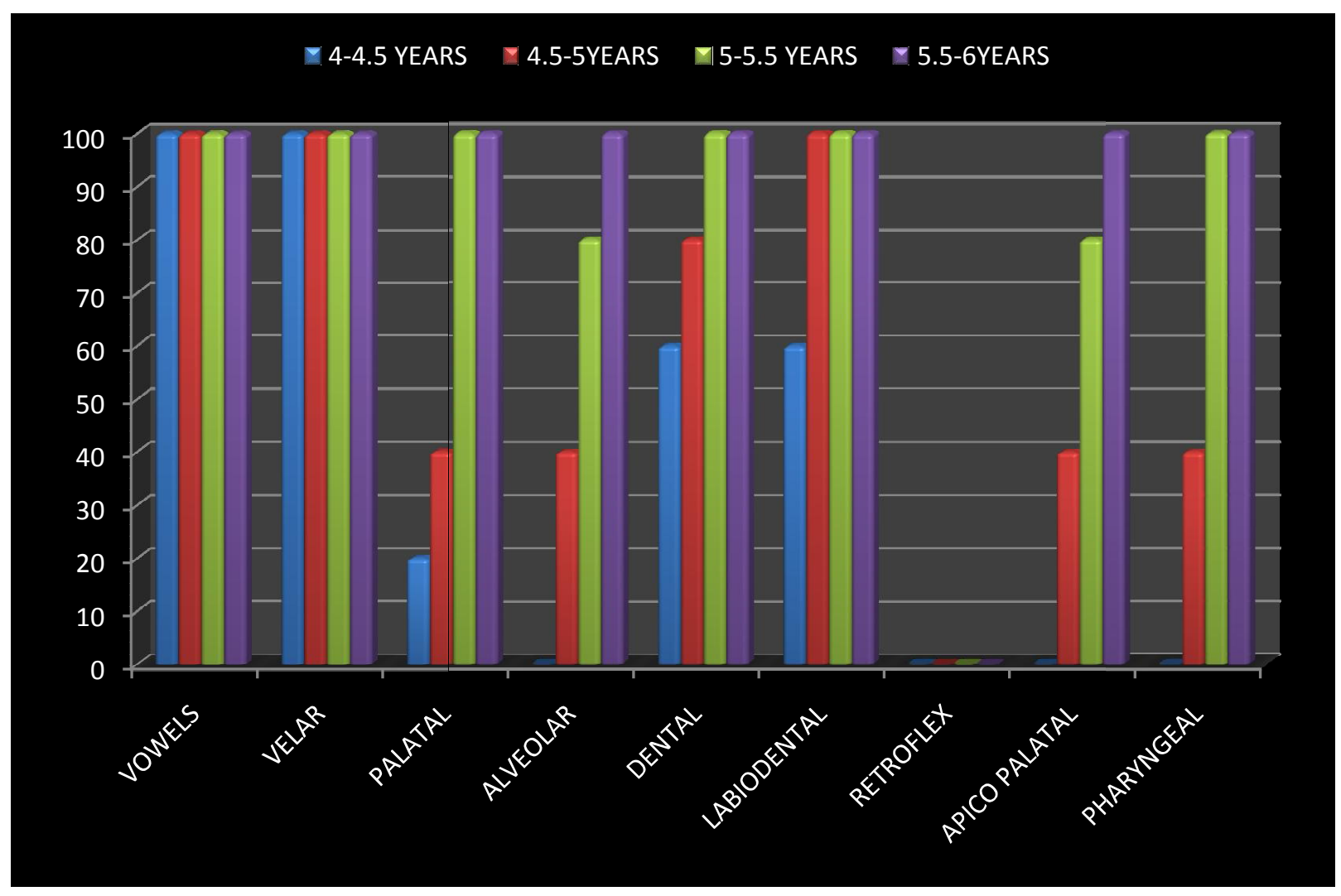

Fig. 1. Development of Consonants and vowels across various age groups among typically developing children

Children with ID: Within group analyses for children with ID shows that, unlike typically developing children, only vowels develop completely by 4 years of age. Velar, dental and labiodental and pharyngeal phonemes initiate only later by around 4.5 years and complete by 6 years of age. However, as seen in Table 4 palatal, alveolar, retroflex and apico palatal phonemes remain under developed even after 6 years of age. Fishers exact test across the age groups shows a highly statistical difference for velar, dental, labiodental and pharyngeal phonemes. This is illustrated in Figure 2.

\section{Constants}

The analyses of consonantal sounds among children with ID reveal that most of the consonants begin to develop by 4 years of age. Unlike, typically developing children, this development does not complete by 6years but continues to develop even beyond that for most of the consonants.
Sounds which complete their development at all positions by 4 years of age are:

1. Bilabial Stops

2. Voiceless Velar Fricatives

\section{Bilabial Nasals}

4. Velar Nasals

\section{Aspirated Bilabial Stops}

Sounds which develop within 4-6 years of age are:

\section{Velar Stops}

2. Bilabial and palatal Semi-Vowels

It is noted that children with ID initiate the development of all the sounds by 6 years of age but the development stays incomplete for almost all the sounds even by 6years. These results are evident in Table 4. 
Descriptive analysis of phonological aspects among Hindi-speaking children

Table 4. Consonant Development among Children with Intellectual Disability

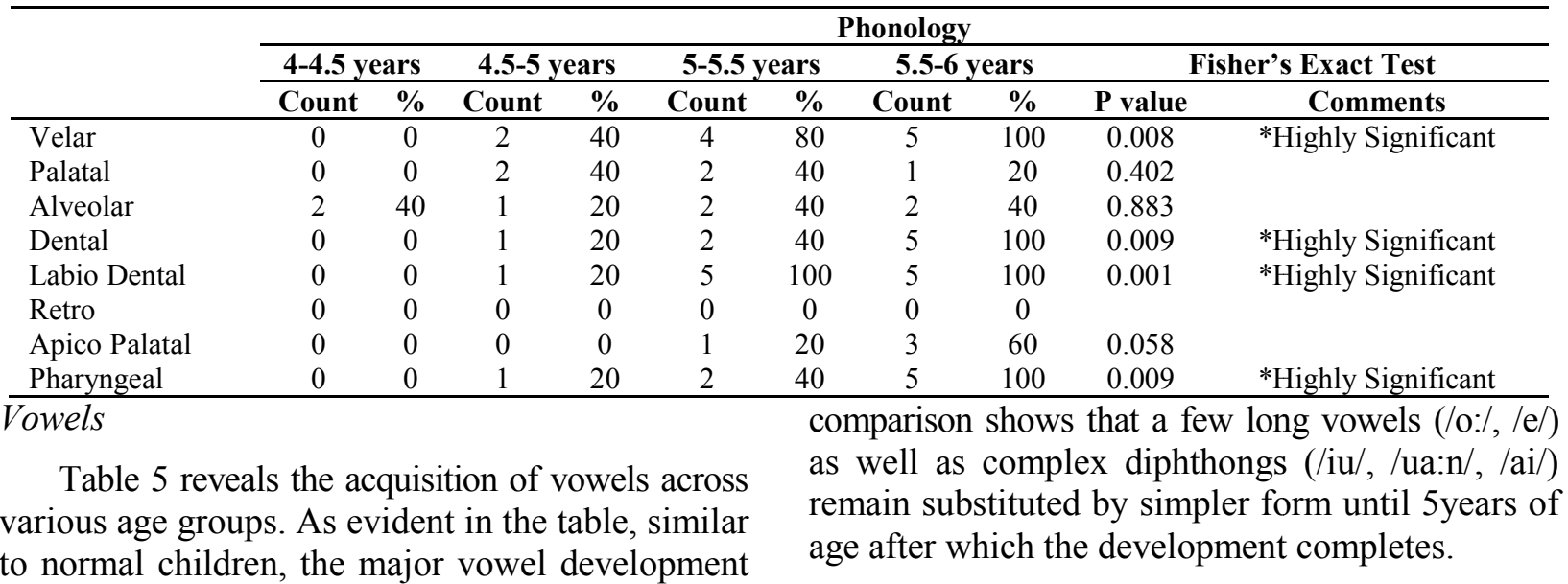
completes by the age of 4 years. The across group

Table 5. Vowel development chart

\begin{tabular}{ccccc}
\hline Vowels & $\mathbf{4 . 0 - 4 . 5}$ years & $\mathbf{4 . 5 - 5 . 0}$ years & $\mathbf{5 . 0 - 5 . 5}$ years & $\mathbf{5 . 5 - 6 . 0 ~ y e a r s ~}$ \\
\hline /a/ & Acquired & Acquired & Acquired & Acquired \\
/a:/ & Acquired & Acquired & Acquired & Acquired \\
/i/ & Acquired & Acquired & Acquired & Acquired \\
/i:/ & Acquired & Acquired & Acquired & Acquired \\
/u/ & Acquired & Acquired & Acquired & Acquired \\
/u:/ & Acquired & Acquired & Acquired & Acquired \\
/e/ & Distorted & Substituted by /ae/ & Acquired & Acquired \\
/o/ & Acquired & Acquired & Acquired & Acquired \\
/o:/ & Substituted by /o/ & Substituted by /o/ & Acquired & Acquired \\
/ae/ & Acquired & Acquired & Acquired & Acquired \\
/ai/ & Substituted by /e/ & Substituted by /e/ & Acquired & Acquired \\
/ia/ & Acquired & Acquired & Acquired & Acquired \\
/ie/ & Acquired & Acquired & Acquired & Acquired \\
/ui/ & Acquired & Acquired & Acquired & Acquired \\
/ua:n/ & Substituted by /ua:/ & Substituted by /ua:/ & Acquired & Acquired \\
/oi/ & Acquired & Acquired & Acquired & Acquired \\
/oe/ & Acquired & Acquired & Acquired & Acquired \\
/iu/ & Substituted by $/ \mathrm{u} /$ & Acquired & Acquired & Acquired \\
\hline
\end{tabular}

Fig. 2. Development of consonants and vowels across various age groups among children with intellectual disability

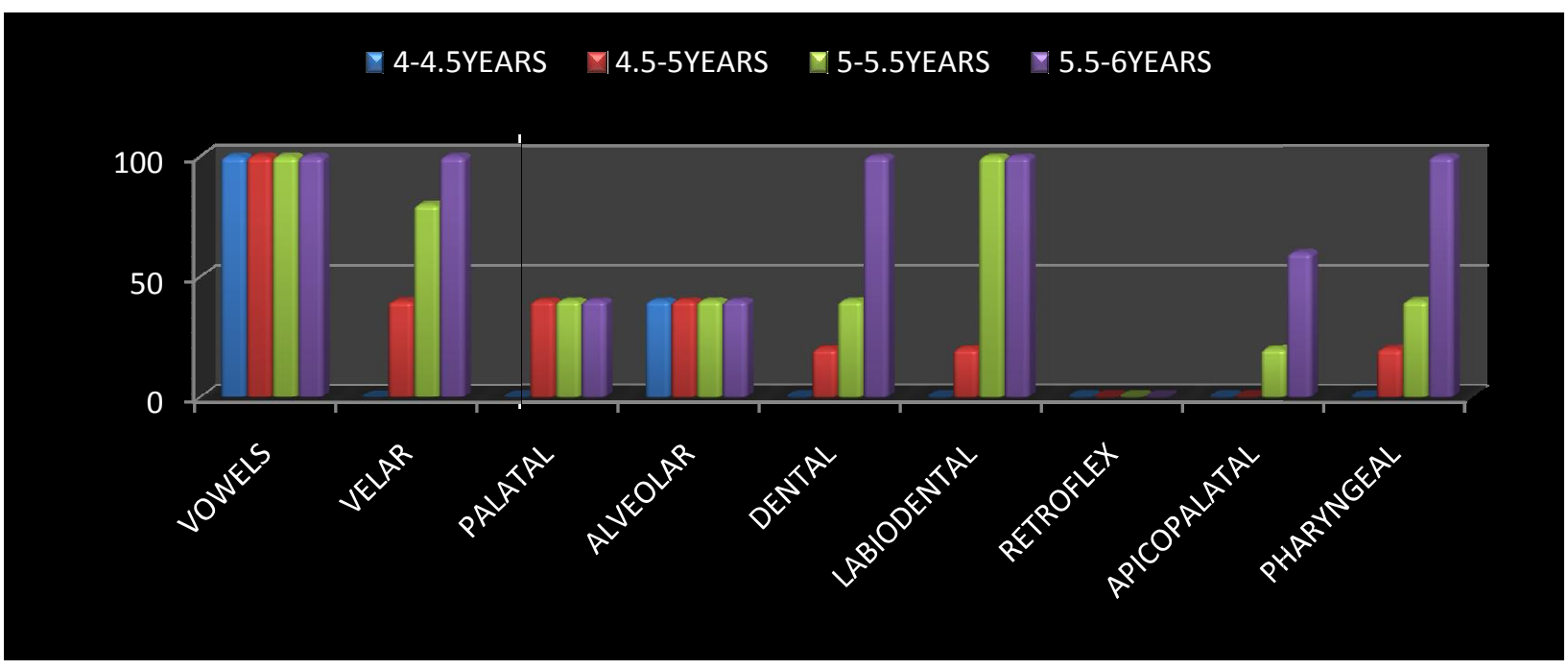




\section{Across Group Comparison}

Comparison of Phonological Aspects across children with ID and controls showed that phonology remained underdeveloped for longer among children with ID.

In case of vowels, both the groups developed vowels similarly by 6years of age. Among the consonants, it was clear that children with ID developed the sounds much later when compared

Table 6. Comparison of Phoneme Development across Typically Developing Children and Children with Intellectual Disability

\begin{tabular}{lcccccc}
\hline & \multicolumn{2}{c}{ Children with ID } & \multicolumn{2}{c}{ TD children } & \multicolumn{2}{c}{ Testing equality of proportion } \\
\cline { 2 - 6 } & Count & $\mathbf{\%}$ & Count & \% & Z value & P \\
\hline Vowels & 20.0 & 100.0 & 20.0 & 100.0 & & \\
Velar & 11.0 & 55.0 & 20.0 & 100.0 & 3.408 & 0.000 \\
Palatal & 5.0 & 25.0 & 13.0 & 65.0 & 2.543 & 0.006 \\
Alveolar & 7.0 & 35.0 & 11.0 & 55.0 & 1.271 & 0.102 \\
Dental & 8.0 & 40.0 & 17.0 & 85.0 & 2.939 & 0.002 \\
Labio Dental & 11.0 & 55.0 & 18.0 & 90.0 & 2.479 & 0.007 \\
Retro & 0.0 & 0.0 & 0.0 & 0.0 & & \\
Apico Palatal & 4.0 & 20.0 & 11.0 & 55.0 & 2.286 & 0.011 \\
Pharyngeal & 8.0 & 40.0 & 12.0 & 60.0 & 1.265 & 0.103 \\
\hline
\end{tabular}

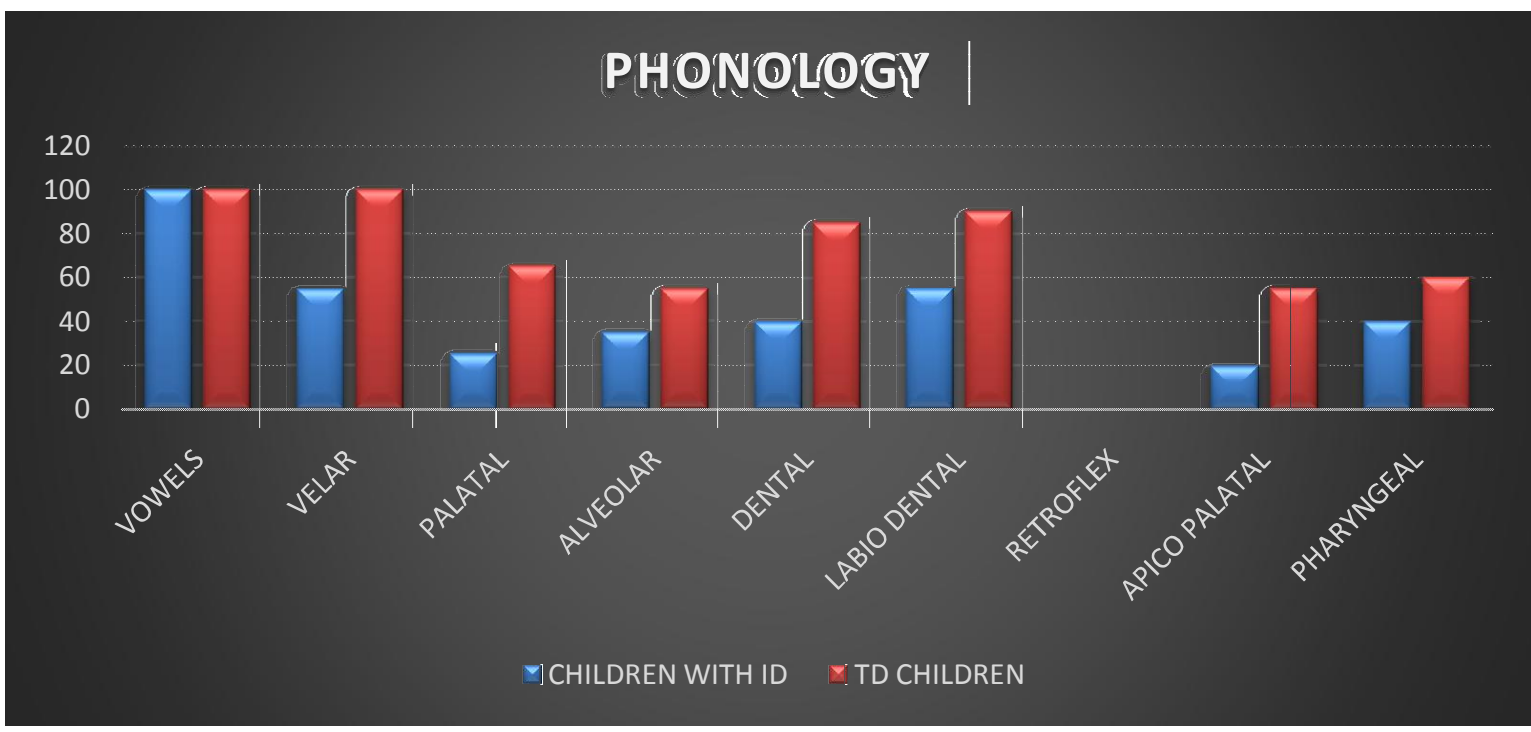

Fig. 3. Phoneme Development across Typically Developing Children and Children with Intellectual Disability

\section{Discussion}

The literature review clearly indicates that the phonological development in a child follows various stages, starting from around two months when vegetative sounds, laughing, and cooing are noted. This is followed by babbling at around four months. Once the child hits the 8-12 month range the child engages in canonical babbling (Owens, 2012). to the age matched controls. As evident from Table 6, velar sounds, palatal sounds, dental and labiodental sounds showed a highly significant difference among the two groups. The other consonant categories namely Alveolar, retroflex, apicopalatal and pharyngeal sounds also developed earlier among Normal children though the difference among the groups was not significant. 
In present study the Phonological analysis showed that TD children developed most of the Hindi phonemes by six years of age, except for a very few complex ones which are either distorted or substituted by simple ones. Similar findings were noted among Kannada speaking children by SubbaRao (1995) and Karanth \& Suchitra (1993) who proposed that 4-6 year old TD children demonstrated all the vowels and consonants of Kannada. Nevertheless, some previous researches in this area noted that phonological acquisition in Kannada is not complete by six years (Tasneem 1977; Prema, 1979). The difference in results of earlier studies can be predicted to be due to variations in the method of collecting data. These observations are in agreement with several western studies also (Carrow-Woolfolk \& Lynch, 1982; Grunwell, 1981; Storkel \& Morrisette, 2002; Paul, 2007; Mc. Namara \& Antony, 2010).

Among intellectually disabled children, the phonological development seemed to be delayed among children with ID when compared to TD children. However, by 6years of age all the phonemes were present among the children with ID, though the scores were lower than typically developing children. The present study co-related with the study by SubbaRao (1995) where both the typically developing and intellectually disabled children showed the presence of all the phonemes in Kannada in their samples. Also, an additional feature of phonological processes was also identified in this study. It was noted that the phonological process were higher among children with ID relative to TD children. This result is similar to a study conducted on children with Down's syndrome by Rupella, Manjula \& Velliman (2010). In addition to this, the present study also agrees that children with ID also show few articulation and fluency issues (Dykens, Hodapp \& Leckman, 1994, Abbedutto, 2004). These continue to make certain articulation errors that reduce or simplify their language (Ingram, 1986; Oller, 2005).

\section{References}

Abbedutto, 2005. Connections between phonology and semantics: an exploration of lexical processing in a language impaired child. Child Language Teaching and Therapy, 9, 3.

American Association on Intellectual \& Developmental Disabilities. (2009). Intellectual Disability: Definition, Classification, and Systems of Supports, 11th Edition. Washington, DC: American Association on Intellectual \& Developmental Disabilities.
American Speech-Language-Hearing Association. (1996). Scope of practice in speech-language pathology. ASHA, 38 (Suppl. 16), 1-4.

Bates, E., Camaioni, L., \& Volterra, V. (1975). The acquisition of performatives prior to speech, Merrill-Palmer Quarterly, 21, 205-224.

Bhat, J. (2002). A study of pragmatics in communicative performance of children with Mental Retardation: A comparison of mental age matched normal children, $A n$ Unpublished Doctoral Thesis Submitted to Manipal University, Mani pal.

Bleile, K. (1982). Consonant ordering in Down syndrome phonology. Journal of Communication Disorder, 15 (4), 275.85.

Brown, R. (1973). A first language. Cambridge, MA: Harvard University Press.

Bruner, J. (1975). From communication to language: A psychological perspective, Cognition, 3 , 255-287.

Bruno, F., Marie-Laure, N., \& Therese. B. (2012). A qualitative analysis of General receptive vocabulary of adolescents with Down syndrome. American journal on Intellectual and developmental Disabilities, 117(3), 243-259.

Caplan, A. (1992).'It's not everyday that parents get a chance to talk like this': Exploring parents' perceptions and expectations of speech-language pathology services for children with intellectual disability. International Journal of Speech-Language Pathology, 12(4), 352-361.

Soltani, A., \& Roslan, S. (2013). Contribution of phonological awareness, Phonological short term memory and rapid automated naming toward decoding ability in students with mild intellectual disability, Research in developmental disabilities, 34(3), 1090-1099.

Stoel-Gammon, C. (1980). Phonological Analysis of four Down's syndrome children, Applied Psycholinguistics, 1, 31-48.

Wells, W. (1985).phonology for conversation: phonetic aspects of turn delimitation, London. Jamaican Journal of Pragmatics. 9. 309-330.

Wise, C, J., Sevick, R, A., Romski, M, A., \& Morris, R, D. (2010). The Relationship between Phonological Processing Skills and Word and Non Word Identification Performance in Children with Mild Intellectual Disabilities, Research in Developmental Disabilities, 31(6), 1170-1175. 